\title{
Association between surgical volumes and hospital mortality in patients: a living donor liver transplantation single center experience
}

\section{Chia-En Hsieh}

Changhua Christian Medical Foundation Changhua Christian Hospital https://orcid.org/0000-00028819-6989

\section{Ya-Lan Hsu}

Changhua Christian Medical Foundation Changhua Christian Hospital

\section{Kuo-Hua Lin}

Changhua Christian Medical Foundation Changhua Christian Hospital

\section{Ping-Yi Lin}

Changhua Christian Medical Foundation Changhua Christian Hospital

\section{Yu-Ju Hung}

Changhua Christian Medical Foundation Changhua Christian Hospital

\section{Yi-Chun Lai}

Changhua Christian Medical Foundation Changhua Christian Hospital

\author{
Li-Chueh Weng ( $\square$ ax2488@mail.cgu.edu.tw) \\ Chang Gung University \\ Yao-Li Chen ( $\nabla$ ylchen.cch@gmail.com ) \\ Changhua Christian Hospital
}

\section{Research article}

Keywords: living donor liver transplantation, hospital mortality, surgical volumes, complication

Posted Date: January 21st, 2021

DOI: https://doi.org/10.21203/rs.3.rs-37446/v2

License: (c) (i) This work is licensed under a Creative Commons Attribution 4.0 International License.

Read Full License 


\section{Abstract}

Background: Many factors cause hospital mortality (HM) after liver transplantation (LT).

Methods: We performed a retrospective research in a single center from October 2005 to June 2019. The study included 463 living donor LT patients. They were divided into a no-HM group $(n=433,93.52 \%)$ and an HM group ( $n=30,6.48 \%$ ). We used logistic regression analysis to determine how clinical features and surgical volume affected HM. We regrouped patients based on periods of surgical volume and analyzed the clinical features.

Results: Multivariate analysis revealed that donor age $(\mathrm{OR}=1.050,95 \% \mathrm{Cl}: 1.011-1.091, \mathrm{p}=0.012)$, blood loss (OR=1.000, 95\% Cl: 1.000-1.000, $p=0.004)$, and annual surgical volumes being < $30 \mathrm{LTs}(\mathrm{OR}=2.540$, $95 \% \mathrm{Cl}: 1.011-6.381, \mathrm{p}=0.047)$ were significant risk factors. A comparison of years based on surgical volume found that when the annual surgical volumes were at least 30 the recipient age $(p=0.023)$, donor age $(p=0.026)$, and $A B O$-incompatible operations $(p<0.001)$ were significantly higher and blood loss $(p<0.001)$, operative time $(p<0.001)$, intensive care unit days $(p<0.001)$, length of stay $(p=0.011)$, rate of re-operation $(p<0.001)$, and $\mathrm{HM}(p=0.030)$ were significantly lower compared to when the annual surgical volumes were less than 30 .

Conclusions: Donor age, blood loss and an annual surgical volume $<30$ LTs were significant pre- and perioperative risk factors. Hospital mortality and annual surgical volume were associated with statistically significant differences; surgical volume may impact quality of care and transplant outcomes.

\section{Background}

Liver transplantation (LT) is a major and difficult abdominal operation, and it involves multiple teams administering such things as anesthesia, color Doppler techniques, and critical care. Living donor liver transplantation (LDLT) was associated with a high rate of surgical complications after transplantation, and the hospital mortality rate after LDLT has ranged from $3.6 \%$ to $18.9 \%$ [1-3]. Factors related to inhospital death include infection, a high model for end-stage liver disease (MELD) score, the recipient being of advanced age, and vascular complications such as hepatic artery thrombosis and portal vein thrombosis [3-4]. Liver transplantation patients commonly acquire nosocomial infections, which can cause morbidity and mortality [5-7]. High MELD scores, large volume of blood loss, post-transplant hemodialysis, $A B O$ incompatibility, and older donor age were independent risk factors for postoperative bacteremia [8-10]. In addition, high MELD scores, restrictive lung patterns and surgical complexity were risk factors with major impacts $[11,12]$.

However, centers with higher surgical volumes (based on annual liver transplantations) had better techniques and multiple team organization compared to centers with lower surgery volumes; higher inhospital mortality was associated with lower surgical volume centers $[1,13]$. In this paper, we therefore mainly analyzed hospital mortality in living donor liver transplant patients and tried to pinpoint the factors that influence postoperative prognosis in order to provide a reference for liver transplant teams. 


\section{Methods}

We performed a retrospective research in Changhua Christian Hospital from October 2005 to June 2019. Living liver grafts were from patients' families, and none of the donors were prisoners who were executed. The study was approved by the Institutional Review Board of Changhua Christian Hospital (CCH 191244). The donors were selected based on general physical condition, blood tests, liver volumetry measured by a computed tomography scan, clinical psychological evaluation, and social assessment. A total of 463 living donor liver transplant patients were included in this study; none of them had combined liver and kidney transplantations. Four of the LTs involved left lobe grafts, and the other 459 involved right lobe grafts. The patients were divided into two groups: the no hospital mortality group $(n=433,93.52 \%)$ and the hospital mortality group $(n=30,6.48 \%)$.

\section{Definitions}

Renal failure (acute or chronic) was defined as the presence of a median glomerular filtration rate $<30$ $\mathrm{mL} / \mathrm{min} / 1.73 \mathrm{~m}^{2}$ for at least 3 to 6 months or the need for long-term dialysis [14]. Biliary complication was defined as the presence of bile leakage or biliary stenosis. Re-operation was defined as the presence of a hemorrhage, vascular thrombosis (portal vein or hepatic artery thrombosis), abdomen abscess, or biliary complication that required another abdominal surgery. Hepatic artery complication was defined as the presence of thrombosis, dissection, stenosis, or steal blood flow with the need for thrombectomy, percutaneous transluminal angioplasty with stenting, or transarterial embolization for steal blood flow from the splenic artery. Portal vein complication was defined as the presence of thrombosis and stenosis with the need for thrombectomy and percutaneous transluminal angioplasty with stenting. Early allograft dysfunction was defined as the presence of at least 1 of the following parameters 7 days after liver transplantation: a serum bilirubin level $\geq 10 \mathrm{mg} / \mathrm{dL}$, an international normalized ratio (INR) $\geq 1.6$ or an alanine or aspartate aminotransferases (ALT or AST) level > 2000 IU/L [15]. Cardiovascular complication was defined as the presence of acute coronary syndrome, acute myocardial infarction or ruptured aortic mycotic aneurysms. Cerebrovascular complication was defined as the presence of subarachnoid hemorrhage, intracerebral hemorrhage, or central pontine myelinolysis. Pulmonary complication was defined as the presence of a lower respiratory tract infection, pneumonia or adult respiratory distress syndrome. Infection complication was defined as the presence of a bloodstream infection, intraabdominal infection, or urinary tract infection. We distinguished pairs of surgical volume periods based on cutoffs of 20,30 , and 50 yearly liver transplantations (Figure 1).

\section{Antimicrobial Prophylaxis}

Prophylaxis was administered intravenously from the day of transplantation. Piperacillin/tazobactam (Tazocin) as well as selective bowel decontamination (neomycin and nystatin administered orally) were used. Routine prophylactic antiviral therapy was not performed.

\section{Immunosuppression}


All patients received calcineurin-inhibitor based initial immunosuppression. The majority also received and were maintained on cyclosporine or tacrolimus in combination with mycophenolate and methylprednisolone. The target levels after the first post-transplant year were as follows: $70-150 \mathrm{ng} / \mathrm{mL}$ for cyclosporine and 5-10 $\mathrm{ng} / \mathrm{mL}$ for tacrolimus. Methylprednisolone was administered intravenously in four divided doses daily; the dosage was tapered from $200 \mathrm{mg} /$ day to $20 \mathrm{mg} /$ day over 6 days.

We had a program for ABO-incompatible patients. First, we administered a preoperative anti-CD20 antibody (rituximab, $375 \mathrm{mg} / \mathrm{m}^{2}$ ) treatment with preoperative plasma exchange to lower the anti-AB antigen titer (1:32); second, we administered a postoperative anti-CD20 antibody (rituximab,

$187.5 \mathrm{mg} / \mathrm{m}^{2}$ ) treatment on post-liver transplantation day 1 . Mycophenolate mofetil was given in doses of $0.5 \sim 1.5 \mathrm{~g} / \mathrm{day}$, and tacrolimus was kept at a trough level of $7-10 \mathrm{ng} / \mathrm{dL}$. When the isoagglutinin titer was above 64 , a plasma exchange was performed to lower the isoagglutinin titer to less than or equal to 64 .

\section{Statistical Analysis}

The pre- and peri-operative periods had correlated clinical factors, including age, gender, MELD score, total bilirubin, creatinine, prothrombin time, INR, graft-recipient weight ratio (GRWR), blood loss, operative time, renal failure (acute or chronic), pre-LT in the intensive care unit, ABO-incompatible liver transplantation and surgical volume. All data were recorded on a computerized database. The patients were classified into two subgroups based on their hospital mortality status, and there were distinguished risk factors of liver transplantation. We regrouped patients based on surgical volume periods and analyzed the demographic data and clinical features. There were comparisons of pre-, peri-, and postoperative characteristics between the high and low surgical volume periods. The clinical post-operative factors included blood loss, operative time, intensive care unit days, length of stay, dialysis, re-operation, biliary complication, hepatic artery complication, portal vein complication, early allograft dysfunction, cardiovascular complication, cerebrovascular complication, pulmonary complication, hemorrhage and infection. Pearson's chi-squared test and the independent t-test were used to examine the differences between the two subgroups in terms of demographic factors and the clinical characteristics of the LDLT patients. Values for the continuous variables are presented as mean \pm standard deviation (SD) in this study. Categorical variables were compared using the chi-squared test or Fisher exact test where appropriate. We used logistic regression analysis to determine how clinical features and surgical volume affected hospital mortality in liver transplantation patients. A p value less than 0.05 was considered to be statistically significant. The statistical analysis was performed with SPSS (Statistical Package for Social Science, version 20.0).

\section{Results}

A total of 463 liver transplant patients were included in this study; they had a hospital mortality rate of $6.88 \%$. The patients were divided into two groups: the no hospital mortality group $(n=433,93.52 \%)$ and the hospital mortality group $(n=30,6.48 \%)$. A comparison between the two groups found statistically significant differences in terms of senior donor age $(p=0.017)$, high MELD score $(p<0.001)$, blood loss 
$(p=0.014)$, annual surgical volume $<30$ liver transplantations $(p=0.030)$, and pre-LT in the intensive care unit $(<0.001$ ) (Table 1). For annual surgical volumes of more than 20,30 , and 50 living donor liver transplantations, the hospital mortality rates were $6.3 \%, 5.4 \%$, and $5.1 \%$, respectively. The 30 surgeries per year cutoff yielded statistically significant differences, unlike the other two cutoffs.

Multivariate analysis revealed that donor age $(\mathrm{OR}=1.050,95 \% \mathrm{Cl}: 1.011-1.091, \mathrm{p}=0.012)$, blood loss (OR=1.000,95\% Cl: $1.000-1.000, p=0.004)$ and annual surgical volume $<30$ liver transplantations $(\mathrm{OR}=2.540,95 \% \mathrm{Cl}: 1.011-6.381, \mathrm{p}=0.047)$ were significant risk factors from the pre- and peri-operative periods (Table 2). The high surgical volume period (annual surgical volume $\geq 30$ liver transplantations) had significantly higher recipient age $(\mathrm{p}=0.023)$, donor age $(\mathrm{p}=0.026)$, and ABO-incompatible rate $(p<0.001)$ and significantly lower blood loss $(p<0.001)$, operative time $(p<0.001)$, intensive care unit days $(p<0.001)$, length of stay $(p=0.011)$, re-operation rate $(p<0.001)$, and hospital mortality rate $(p=0.030)$ compared to the low surgical volume period (annual surgical volume $<30$ liver transplantations) (Table 3 ).

The most common cause of hospital death was infection $(n=13,43.3 \%)$, and other causes often coincided with infection: hemorrhage with/without infection $(n=4,13.3 \%)$, cerebrovascular with/without infection $(n=3,10.0 \%)$, cardiovascular with/without infection $(n=6,20.0 \%)$, and early allograft dysfunction with infection $(n=4,13.3 \%)$. Most causes of patient death were major post-LT complications, which developed into septic shock and led to mortality. In the hospital mortality group, the high surgical volume period (annual surgical volume $\geq 30$ liver transplantations) had significantly lower rates of hemorrhage $(p=<0.001)$, cerebrovascular complication $(p<0.001)$, and cardiovascular complication $(p<0.001)$ and a significantly higher rate of early allograft dysfunction $(p<0.001)$ compared to the low surgical volume period (annual surgical volume $<30$ liver transplantations) by nonparametric statistics. (Table 4).

\section{Discussion}

A comparison by multivariate analysis between the hospital mortality group and the no hospital mortality group found high donor age, high blood loss and annual surgery volume $<30$ liver transplantations to be statistically significant risk factors. Annual LDLT volume was less than 10 cases in the first 5 years of our transplantation center (Figure 1). It was a little surprising that the outcome for the period with $<20$ annual cases and the outcome for the period with $\geq 20$ annual cases were not statistically different. When the case volumes were small, we were more cautious in that selected recipients had lower MELD scores, the GRWR was kept above $0.8 \%$ and safe donor grafts were used (normal vessel or biliary tract anatomy). The first 15-20 LDLT cases are associated with a significant surgery learning curve $[16,17]$. Annual surgery volume grew to 20-30 cases in the $6^{\text {th }}$ and $7^{\text {th }}$ years; there were more urgent patients with acute liver failure conditions, including some recipients with rapid development of hepatic dysfunction associated with encephalopathy or renal failure. By putting the recipient in a positive pressure isolation room with 2 beds in the intensive care unit, the nosocomial infection risk was reduced. Over the period with 30 to 50 annual cases, we used soft power of critical care training and continuing education of the staffs. An important point is that multidisciplinary characteristics such as integration and organization management add to the operative learning curve (multiple anastomoses of vessel or biliary tract 
anatomy). The training of the multidisciplinary staffs covered color Doppler techniques, anesthesia, critical care, rejection identification and infection treatment. We have a combined intensivist in infectious diseases and critical care, and we established a specialized liver transplantation ward. Thus, we had put infrastructure in place to ensure favorable outcomes. Operative time, blood loss, re-operation, intensive care unit days, length of stay and hospital mortality decreased significantly after annual surgical volume reached 30 cases. After improving soft power and care quality, our physical selection criteria became less strict in regard to senior recipients, donor age, the GRWR lower bound (range 0.55-0.8), ABO-incompatible liver transplantation, and multiple hepatic duct or portal vein anastomoses, which were not limiting factors or difficult techniques. However, neither portal vein complications nor early allograft dysfunction led to a significantly higher mortality rate. In addition, the hospital mortality rate when the annual surgical volume was less than 20 liver transplantations was $10.5 \%$, and it decreased to $5.4 \%$ and $5.1 \%$ when annual surgical volume was $\geq 30$ and $\geq 50$ liver transplantations, respectively.

The complications with the highest mortality rates were cerebrovascular problems, including subarachnoid and intracerebral hemorrhages $[18,19]$. Common early postoperative complications following LDLT include thrombosis in reconstructed major blood vessels (portal vein or hepatic artery reconstructed with an artificial vascular graft or cryopreserved vein grafts) [20]. In the absence of ongoing bleeding after operation, our center considered maintaining an INR between 1.5 and 2, a platelet count $>50,000 / \mu \mathrm{L}$ and a fibrinogen level $>100 \mathrm{mg} / \mathrm{dL}$ as satisfactory. Hypertension occurs usually in the initial treatment when the systolic blood pressure is greater than $160 \mathrm{mmHg}$ or the diastolic blood pressure is greater than $100 \mathrm{~mm} \mathrm{Hg}$. In the general population, intracranial hemorrhage may occur in association with coagulopathy, acute hypertension or chronic hypertension. An intracranial or subarachnoid hemorrhage after liver transplantation that requires immediate craniotomy and removal of a hematoma may be combined with nosocomial infections and result in high mortality. Postoperatively, blood pressure and fibrinogen levels can be monitored closely to help prevent post-transplant intracranial hemorrhages [18].

In our center's policy, when old age, cardiomegaly, history of coronary artery disease (CAD), or massive ascites is a trait in an alcoholic cirrhosis patient, the patient undergoes regular electrocardiograms and echocardiographies for pre-operative cardiovascular assessment of LT. If the patient is an LT candidate, then dobutamine stress myocardial perfusion scanning is performed for detection of CAD. Active coronary artery disease is a relative contraindication to liver transplantation and at a minimum should be treated as aggressively as possible preoperatively (stenting, angioplasty). For high cardiopulmonary risk patients, we evaluated their hemodynamic measurements by pulmonary artery catheter. Cardiac dysfunction and moderate to severe portopulmonary hypertension (mean pulmonary arterial pressure $\geq$ $35 \mathrm{mmHg}$ and elevated pulmonary vascular resistance) were diagnosed and were considered contraindications of liver transplantation [21]. Cardiovascular complications occurred in 8 patients after LDLT. Two patients survived. One survivor had arrhythmia with atrial fibrillation, paroxysmal supraventricular tachycardia, ventricular tachycardia and ventricular fibrillation in the first week after liver transplantation. The recurrent arrhythmia was poorly controlled by anti-arrhythmia treatment and defibrillation. Careful laboratory monitoring and supplementation were warranted; electrolytes were provided to maintain a normal level. An echocardiography showed moderate mitral regurgitation and 
tricuspid regurgitation. Still, anti-arrhythmia treatment did not prevent the arise of severe bradycardia with atrioventricular block. The discontinuation of antiarrhythmic drug therapy showed no significant improvement, and a cardiologist suggested inserting temporary pacemakers. The other surviving patient's electrocardiogram presented ST elevation and increased levels of myocardial enzymes. Percutaneous coronary intervention was done to exclude an obvious problem.

The other 6 cases with cardiovascular complications resulted in hospital mortality. One case involved the rupture of an aortic mycotic aneurysm after transplantation. This patient had a diagnosis of abdominal mycotic aneurysms and infection by salmonella species in pre-transplantation image evaluation. Treatments of patients with mycotic aneurysms caused by salmonella should include antibiotic therapy and surgery [22]. This patient had a high MELD score and massive ascites; a cardiovascular surgeon recommended antibiotic therapy and endovascular stent repair after liver transplantation. On the $12^{\text {th }}$ day after liver transplantation, a rupture of an aortic mycotic aneurysm resulted in emergency surgery; the cause of death was hemorrhage. Surgery as an early-stage prevention of aneurysm rupture may decrease morbidity or mortality [22]. In three cases, cardiac arrest occurred within 2-5 minutes after reperfusion in intraoperative status. They experienced high-quality cardiopulmonary resuscitation, but their hemodynamic conditions remained unstable. They were then placed on extra-corporeal membrane oxygenation (ECMO). The $2^{\text {nd }}$ case had hyperkalemia combined with acidosis due to a massive intraoperative blood transfusion and renal failure history. In the $3^{\text {rd }}$ and $4^{\text {th }}$ cases, CAD and pulmonary embolism diagnoses were ruled out by percutaneous coronary intervention. Cardiac death within 5 minutes after graft reperfusion may result from many possible causes, including hyperkalemia, acidosis, pulmonary embolism, hypothermia, arrhythmia, cardiac tamponade, acute heart failure, and myocardial infarction $[23,24]$. We finally reached the diagnoses of acute coronary syndrome. The patients' conditions were hemodynamically stable, and their ECMOs were successfully removed after a few days. However, they suffered from cardiac arrest in the ICU. In the $5^{\text {th }}$ case, we diagnosed acute coronary syndrome by percutaneous coronary intervention, and the $6^{\text {th }}$ case showed mild pulmonary hypertension by echocardiography. Both cases developed septic shock. CAD was found to be the leading cause of early mortality, and it was followed by infection [25]. Cardiovascular complications are the main cause of nongraft-related mortality after LT.

Early allograft dysfunction occurred in 10 cases after LDLT. Successful liver function recovery occurred in 2 cases. Six cases resulted in additional liver transplantations ( 2 case deaths from severe sepsis), and 2 cases resulted in death while waiting for graft liver. An analysis revealed that causes of early allograft dysfunction are high MELD score ( $\geq 35$ ) combined with low GRWR (range $0.67 \sim 0.69$ ), hepatic steatosis (moderate) in the donor graft and senior donor age (59 and 65 years). The donor's age and moderate and severe steatosis were already established risk factors for early allograft dysfunction or primary graft dysfunction or non-function [26-30]. Donor age ( $\geq 50$ years) was an independent risk factor to affect regeneration after transplant [26]. Effective graft regeneration may be associated with stem cells or progenitor cells in an elderly donor's liver [9]. The best survival results in our study were observed when the MELD score was below 15. Those with low MELD scores ( $n=2$, MELD 7 and 13) could better tolerate 
an initial graft dysfunction than the recipients with medium or higher MELD scores who were not achieving successful transplantations due to hepatic steatosis (moderate), senior donor age, or a smallsized graft $(G R W R<0.7)$ succumbing to early allograft dysfunction or graft failure. Values above this limit constitute important factors associated with post-transplant hospital mortality [28-30]. This should also be taken into account when deciding whether to transplant.

Many studies have analyzed the association between hospital mortality and transplantation volume in centers $[1,5]$. Our study analyzed the association between surgeon volume (LT cases) and hospital mortality. The early phase of a surgeon's LDLT practice involves frustration and numerous hardships. Massive blood loss, long operative time, prolonged mechanical ventilation, and post-operative complications lead to sepsis and early hospital mortality. Our center is a non-metropolitan hospital; decisive transplant leadership and team staff centripetal force were absolutely essential. Transplant leadership made decisions on valid multidisciplinary integration and organization management. We found a statistically significant association between hospital mortality and surgical volume. This study has some limitations. This study excluded deceased donor liver transplants. Our center only performed 4 to 8 deceased donor liver transplants per year due to a shortage of available organs in Taiwan, and initial development was lower liver graft. An LDLT department needs multidisciplinary integration and organization management. In sharing the development experience of our center, we believe all emerging centers must have access to mentoring while developing an LDLT program.

\section{Conclusions}

Donor age, blood loss and a surgical volume $<30$ yearly liver transplantations were significant risk factors from the pre- and peri-operative periods. A comparison showed that annual surgical volumes $\geq 30$ liver transplantations had significantly lower blood loss, operative time, intensive care unit days, length of stay, re-operation rate, and hospital mortality than annual surgical volumes $<30$ liver transplants. In hospital mortality patients, annual surgical volumes $\geq 30$ liver transplantations had significantly lower rates of hemorrhage, cerebrovascular complication, and cardiovascular complication and a significantly higher rate of early allograft dysfunction than annual surgical volumes $<30$ liver transplantations. During the annual surgical volume $\geq 30$ period, we practiced more soft power; this may impact quality of care and therefore transplant outcomes.

\section{Abbreviations}

LT: liver transplantation; LDLT: living donor liver transplantation; MELD: model for end-stage liver disease; IVC: inferior vena cava; INR: international normalized ratio; ALT: alanine aminotransferase; GRWR: graftrecipient weight ratio; $C A D$ : coronary artery disease; ECMO: extra-corporeal membrane oxygenation.

\section{Declarations}

Ethics approval and consent to participate: 
The study was approved by the Institutional Review Board of the Changhua Christian Hospital (No. CCH 191244).

\section{Consent for publication:}

Not applicable.

\section{Availability of data and materials:}

Ethical restrictions prohibit the authors from making the data publicly available in order to protect patient confidentiality and privacy. Interested researchers can submit data access requests to the Changhua Christian Hospital Institutional Data Access.

\section{Competing interests:}

The authors declare that they have no conflicts of interest.

\section{Funding:}

This research did not receive any specific grant from funding agencies in the public, commercial, or notfor-profit sectors.

\section{Author`s Contributions:}

CEH, YLH, YLC, and LCW designed the study, wrote the manuscript and helped to acquire and interpret the data. PYL, YJH, and YCL helped with the data management and interpretation. YJH and YCL acquired the data. KHL, PYL, and LCW developed the analytical method and analyzed the samples. CEH and YLH helped to interpret the data and to write the manuscript. CEH, KHL, YLC, and LCW provided critical review. All authors read and approved the final manuscript.

\section{Acknowledgements:}

Not Applicable.

\section{References}

1. Yoo S, Jang EJ, Yi NJ, Kim GH, Kim DH, Lee H, Jung CW, Ryu HG. Effect of Institutional Case Volume on In-hospital Mortality After Living Donor Liver Transplantation: Analysis of 7073 Cases Between 2007 and 2016 in Korea. Transplantation. 2019;103(5):952-8.

2. Kim YJ, Yoon JH, Kim SI, Choi HJ, Choi JY, Yoon SK, You YK, Kim DG. Impact of Pretransplant Infections on Clinical Course in Liver Transplant Recipients. Transplant Proc. 2018;50(4):1153-6.

3. Kaido T, Egawa H, Tsuji H, Ashihara E, Maekawa T, Uemoto S. In-hospital mortality in adult recipients of living donor liver transplantation: experience of 576 consecutive cases at a single center. Liver Transpl. 2009;15(11):1420-5. 
4. Gil E, Kim JM, Jeon K, Park H, Kang D, Cho J, Suh GY, Park J. Recipient Age and Mortality After Liver Transplantation: A Population-based Cohort Study. Transplantation. 2018;102(12):2025-32.

5. Chu MJ, Dare AJ, Phillips AR, Bartlett AS. Donor Hepatic Steatosis and Outcome After Liver Transplantation: a Systematic Review. J Gastrointest Surg. 2015;19(9):1713-24.

6. Laici C, Gamberini L, Bardi T, Siniscalchi A, Reggiani MLB, Faenza S. Early infections in the intensive care unit after liver transplantation-etiology and risk factors: A single-center experience. Transpl Infect Dis. 2018;20(2):e12834.

7. Sang II Kim. Bacterial infection after liver transplantation. World J Gastroenterol. 2014;20(20):621120.

8. lida T, Kaido T, Yagi S, Yoshizawa A, Hata K, Mizumoto M et al. Posttransplant bacteremia in adult living donor liver transplant recipients. Liver Transpl. 2010;16(12):1379-85.

9. Hara T, Soyama A, Takatsuki M, Hidaka M, Carpenter I, Kinoshita A, Adachi T, Kitasato A, Kuroki T, Eguchi S. The impact of treated bacterial infections within one month before living donor liver transplantation in adults. Ann Transplant. 2014;19:674-9.

10. Hsieh CE, Chen YL, Lin PY, Lin KH, Lin HC, Liu CE, Wang SH, Li YL. Liver transplantation in patients infected with gram-negative bacteria: non-Acinetobacter baumannii and Acinetobacter baumannii. Transplant Proc. 2013;45(1):225-30.

11. Avolio AW, Gaspari R, Teofili L, Bianco G, Spinazzola G, Soave PM, Paiano G, Francesconi AG, Arcangeli A, Nicolotti N, et al. Postoperative respiratory failure in liver transplantation: Risk factors and effect on prognosis. PLoS One. 2019;14(2):e0211678.

12. Levesque E, Hoti E, Azoulay D, Honore I, Guignard B, Vibert E, Ichai P, Antoun F, Saliba F, Samuel D. Pulmonary complications after elective liver transplantation-incidence, risk factors, and outcome. Transplantation. 2012;94(5):532-8.

13. Yoo S, Jang EJ, Kim GH, Kim DH, Kwon SM, Lee H, Jung CW, Ryu HG. Effect of Institutional Case Volume on In-Hospital Mortality After Deceased Donor Liver Transplantation: A Nationwide Retrospective Cohort Study in Korea. Transplant Proc. 2018;50(10):3644-9.

14. Pawarode A, Fine DM, Thuluvath PJ. Independent risk factors and natural history of renal dysfunction in liver transplant recipients. Liver Transpl. 2003;9(7):741-7.

15. Olthoff KM, Kulik L, Samstein B, Kaminski M, Abecassis M, Emond J, Shaked A, Christie AD. Validation of a current definition of early allograft dysfunction in liver transplant recipients and analysis of risk factors. Liver Transpl. 2010(8):943-9.

16. Manas D, Burnapp L, Andrews PA. Summary of the British Transplantation Society UK Guidelines for Living Donor Liver Transplantation. Transplantation. 2016;100(6):1184-90.

17. Miller CM, Quintini C, Dhawan A, Durand F, Heimbach JK, Kim-Schluger HL, Kyrana E, Lee SG, Lerut J, Lo CM, et al. The International Liver Transplantation Society Living Donor Liver Transplant Recipient Guideline. Transplantation. 2017;101(5):938-44.

18. Gallagher TK, Thomas KA, Ladner DP, Ganger D, Sorond FA, Prabhakaran S, Abecassis MM, Fryer JP, Liotta EM. Incidence and Risk Factors of Intracranial Hemorrhage in Liver Transplant Recipients. 
Transplantation. 2018;102(3):448-53.

19. Ling L, He X, Zeng J, Liang Z. In-hospital cerebrovascular complications following orthotopic liver transplantation: A retrospective study. BMC Neurol. 2018;8:52.

20. Miller CM, Quintini C, Dhawan A, Durand F, Heimbach JK, Kim-Schluger HL, Kyrana E, Lee SG, Lerut J, Lo CM, et al. The International Liver Transplantation Society Living Donor Liver Transplant Recipient Guideline. Transplantation. 2017;101(5):938-44.

21. Dalal A. Anesthesia for liver transplantation. Transplant Rev (Orlando). 2016;30(1):51-60.

22. Guo Y, Bai Y, Yang C, Wang P, Gu L. Mycotic aneurysm due to Salmonella species: clinical experiences and review of the literature. Braz J Med Biol Res. 2018;51(9):e6864.

23. Matsusaki T, Hilmi IA, Planinsic RM, Humar A, Sakai T. Cardiac arrest during adult liver transplantation: a single institution's experience with 1238 deceased donor transplants. Liver Transpl. 2013;19(11):1262-71.

24. Shi $X Y, X u Z D, X u H T$, Jiang JJ, Liu G. Cardiac arrest after graft reperfusion during liver transplantation. Hepatobiliary Pancreat Dis Int. 2006;5(2):185-9.

25. VanWagner LB, Lapin B, Levitsky J, Wilkins JT, Abecassis MM, Skaro Al, et al. High early cardiovascular mortality after liver transplantation. Liver Transpl. 2014;20(11):1306-16.

26. Tanemura A, Mizuno S, Wada H, Yamada T, Nobori T, Isaji S. Donor age affects liver regeneration during early period in the graft liver and late period in the remnant liver after living donor liver transplantation. World J Surg. 2012;36:1102-011.

27. Serste T, Bourgeois N. Ageing and the liver. Acta Gastroenterol Belg. 2006;69:296-8.

28. Salviano MEM, Lima AS, Tonelli IS, Correa HP, Chianca TCM. Primary liver graft dysfunction and nonfunction: integrative literature review. Rev Col Bras Cir. 2019;46(1):e2039.

29. Hudcova J, Scopa C, Rashid J, Waqas A, Ruthazer R, Schumann R. Effect of early allograft dysfunction on outcomes following liver transplantation. Clin Transplant. 2017;31(2):e12887.

30. Sharkey FE, Lytvak I, Prihoda TJ, Speeg KV, Washburn WK, Halff GA. High-grade microsteatosis and delay in hepatic function after orthotopic liver transplantation. Hum Pathol. 2011;42(9):1337-42.

\section{Tables}

Table 1. Comparisons of demographic data and pre- and peri-operative clinical features based on hospital mortality in liver transplantation patients 


\begin{tabular}{|c|c|c|c|}
\hline Demographic and clinical features & No hospital mortality $(n=433)$ & Hospital mortality $(\mathrm{n}=30)$ & $\mathrm{p}$ \\
\hline & Mean \pm SD (range) & Mean \pm SD (range) & \\
\hline Recipient age (years) & $54.08 \pm 8.41(11-73)$ & $52.43 \pm 11.66(21-73)$ & 0.453 \\
\hline Donor age (years) & $31.12 \pm 9.15(18.0-65.00)$ & $35.27 \pm 9.28(20.0-56.00)$ & 0.017 \\
\hline MELD score & $17.59 \pm 9.31(3.0-40.0)$ & $23.33 \pm 9.32(9.0-37.0)$ & $<0.001$ \\
\hline Total bilirubin (mg/dL) & $6.89 \pm 9.62(0.19-47.69)$ & $8.75 \pm 10.33(0.32-38.68)$ & 0.314 \\
\hline Creatinine ( $\mathrm{mg} / \mathrm{dL})$ & $1.16 \pm 0.96(0.32-8.65)$ & $1.55 \pm 1.10(0.40-4.90)$ & 0.075 \\
\hline INR & $1.53 \pm 0.638(0.87-4.76)$ & $1.69 \pm 0.62(0.95-3.64)$ & 0.201 \\
\hline GRWR & $1.10 \pm 0.30(0.55-2.28)$ & $1.13 \pm 0.33(0.68-2.04)$ & 0.617 \\
\hline Blood loss (ml) & $\begin{array}{c}3478.10 \pm 3656.62 \\
(300.0-39450.0)\end{array}$ & $\begin{array}{c}7003.00 \pm 7371.99 \\
(200.0-40000.0)\end{array}$ & 0.014 \\
\hline \multirow[t]{2}{*}{ Operative time (min) } & $408.79 \pm 93.87(215.00-855.00)$ & $434.33 \pm 105.65(280.00-660.00)$ & 0.154 \\
\hline & $(\%)$ & $(\%)$ & \\
\hline Gender & & & 0.859 \\
\hline (Male) & $338(78.1)$ & $23(76.7)$ & \\
\hline (Female) & 95 (21.9) & $7(23.3)$ & \\
\hline The type of disease & & & 0.087 \\
\hline (Alcoholic \pm viruses) & $108(24.9)$ & $13(43.3)$ & \\
\hline (Virus related) & $284(65.6)$ & $13(43.3)$ & \\
\hline (Primary biliary cholangitis) & $8(1.8)$ & $1(3.3)$ & \\
\hline (Other) & $33(7.6)$ & $3(10.0)$ & \\
\hline Pre-LT renal failure & & & 0.197 \\
\hline (Yes) & $21(4.8)$ & $3(10.0)$ & \\
\hline (No) & 412 (93.8) & $27(90.0)$ & \\
\hline Pre-LT in intensive care unit & & & 0.001 \\
\hline (Yes) & $27(6.2)$ & 7 (23.3) & \\
\hline (No) & $406(93.8)$ & $23(76.7)$ & \\
\hline ABO incompatible & & & 1.000 \\
\hline (Yes) & $51(11.8)$ & $3(10.0)$ & \\
\hline (No) & $382(88.2)$ & $27(90.0)$ & \\
\hline \multicolumn{4}{|l|}{ Liver transplant cases / year } \\
\hline$(<20 /$ year $)$ & $17(3.9)$ & $2(6.7)$ & 0.353 \\
\hline$(\geq 20 /$ year $)$ & $416(96.1)$ & $28(93.3)$ & \\
\hline$(<30 /$ year $)$ & $65(15.0)$ & $9(30.0)$ & 0.030 \\
\hline$(\geq 30 /$ year $)$ & $368(85.0)$ & $21(70.0)$ & \\
\hline$(<50 /$ year $)$ & $135(31.2)$ & $14(46.7)$ & 0.079 \\
\hline$(\geq 50 /$ year $)$ & $298(68.8)$ & $16(53.3)$ & \\
\hline
\end{tabular}

Note: model for end-stage liver disease (MELD) score, international normalized ratio (INR), graft-recipient weight ratio (GRWR), liver transplantation (LT). The types of disease were alcoholic $(n=102,22.0 \%)$, alcoholic \pm hepatitis B or C $(n=19,4.1 \%)$, hepatitis B $(n=165,35.6 \%)$, hepatitis C $(n=110,23.8 \%)$, hepatitis B and C $(n=22,4.8 \%)$, primary biliary cholangitis $(n=9$, $1.9 \%)$ and other $(n=36,7.8 \%)$ : non-hepatitis $B$ and $C(n=25)$, autoimmune $(n=6)$, drug toxicity $(n=1)$, liver tumor $(n=4)$. 
Table 2. Logistic regression analysis of factors affecting clinical features of hospital mortality in liver transplantation patients

\begin{tabular}{ccccccc}
\hline & \multicolumn{3}{c}{ Univariate analysis } & \multicolumn{2}{c}{ Multivariate analysis } \\
\hline Variable & OR & $95 \%$ CI & $\mathrm{p}$ & OR & $95 \%$ CI & $\mathrm{p}$ \\
Recipient age (years) & 0.979 & $0.941-1.020$ & 0.313 & - & - & - \\
Donor age (years) & 1.044 & $1.007-1.083$ & 0.019 & 1.050 & $1.011-1.091$ & 0.012 \\
MELD score & 1.065 & $1.026-1.104$ & 0.001 & 1.041 & $0.994-1.091$ & 0.090 \\
Total bilirubin (mg/dL) & 1.019 & $0.985-1.054$ & 0.278 & - & - & - \\
Creatinine ( mg/dL) & 1.292 & $0.999-1.692$ & 0.051 & - & - & - \\
INR & 1.370 & $0.842-2.229$ & 0.205 & - & - & - \\
GRWR & 1.355 & $0.413-4.492$ & 0.617 & - & - & - \\
Blood loss (ml) & 1.000 & $1.000-1.000$ & $<0.001$ & 1.000 & $1.000-1.000$ & 0.004 \\
Operative time (min) & 1.003 & $0.999-1.006$ & 0.155 & - & - & - \\
<20 LT cases/year & 1.748 & $0.384-7.946$ & 0.470 & - & - & - \\
<30 LT cases/year & 2.426 & $1.064-5.532$ & 0.035 & 2.540 & $1.011-6.381$ & 0.047 \\
<50 LT cases /year & 1.931 & $0.916-4.071$ & 0.084 & - & - & - \\
Male & 0.859 & $0.385-2.218$ & 0.859 & - & - & - \\
Pre-LT renal failure & 2.180 & $0.612-7.769$ & 0.229 & - & - & - \\
Pre-LT in ICU & 4.576 & $1.803-11.616$ & 0.001 & 2.381 & $0.723-7.845$ & 0.154 \\
ABO incompatible & 0.832 & $0.244-2.842$ & 0.769 & - & - & - \\
\hline
\end{tabular}

Note: model for end-stage liver disease (MELD) score, international normalized ratio (INR), graft-recipient weight ratio (GRWR), liver transplantation (LT), intensive care unit (ICU)

Table 3. Comparisons of demographic data and clinical features of surgical volume periods in liver transplantation patients 


\begin{tabular}{|c|c|c|c|}
\hline \multicolumn{3}{|c|}{ Demographic and clinical features annual surgical volumes $<30(n=74)$ annual surgical volumes $\geq 30(n=389)$} & \multirow[t]{2}{*}{$\mathrm{p}$} \\
\hline & Mean \pm SD (range) & Mean \pm SD (range) & \\
\hline Recipient age (years) & $51.88 \pm 9.33(11-70)$ & $54.37 \pm 8.48(18-73)$ & 0.023 \\
\hline Donor age (years) & $29.22 \pm 8.13(18.0-54.00)$ & $31.80 \pm 9.34(18.0-65.00)$ & 0.026 \\
\hline MELD score & $17.32 \pm 8.95(6.0-40.0)$ & $17.68 \pm 9.43(3.0-40.0)$ & 0.661 \\
\hline Total bilirubin (mg/dL) & $6.01 \pm 9.10(0.19-47.69)$ & $7.01 \pm 9.72(0.32-37.94)$ & 0.387 \\
\hline Creatinine ( $\mathrm{mg} / \mathrm{dL})$ & $1.13 \pm 0.81(0.38-4.90)$ & $1.20 \pm 0.99(0.32-8.65)$ & 0.764 \\
\hline INR & $1.57 \pm 0.71(0.92-4.59)$ & $1.54 \pm 0.62(0.87-4.76)$ & 0.678 \\
\hline GRWR & $1.15 \pm 0.31(0.65-2.16)$ & $1.08 \pm 0.30(0.55-2.28)$ & 0.105 \\
\hline Blood loss (ml) & $\begin{array}{c}6143.92 \pm 5202.98 \\
(200.0-23000.0)\end{array}$ & $\begin{array}{c}3242.82 \pm 3661.38 \\
(200.0-40000.0)\end{array}$ & $<0.001$ \\
\hline Operative time (min) & $474.51 \pm 91.78(290.00-730.00)$ & $398.26 \pm 90.24(215.00-885.00)$ & $<0.001$ \\
\hline APACHE II score & $17.55 \pm 7.00(5.00-29.00)$ & $18.46 \pm 7.24(3.00-37.00)$ & 0.318 \\
\hline Intensive care unit (days) & $15.23 \pm 10.03(4.0-58.00)$ & $9.63 \pm 9.64(1.00-114.00)$ & $<0.001$ \\
\hline \multirow[t]{2}{*}{ Length of stay (days) } & $35.55 \pm 17.38(14.00-119.00)$ & $29.89 \pm 17.38(3.00-159.00)$ & 0.011 \\
\hline & (\%) & (\%) & \\
\hline Gender & & & 0.081 \\
\hline (Male) & $52(70.3)$ & $309(79.4)$ & \\
\hline (Female) & $22(29.7)$ & $80(20.6)$ & \\
\hline Pre-LT renal failure & & & 0.633 \\
\hline (Yes) & $3(4.1)$ & $21(5.4)$ & \\
\hline (No) & $71(95.9)$ & $368(94.6)$ & \\
\hline Pre-LT in intensive care unit & & & 0.237 \\
\hline (Yes) & $3(4.1)$ & $31(8.0)$ & \\
\hline (No) & $71(95.9)$ & $358(92.0)$ & \\
\hline ABO incompatible & & & $<0.001$ \\
\hline (Yes) & $0(0.0)$ & $54(13.9)$ & \\
\hline (No) & $74(100.0)$ & $335(86.1)$ & \\
\hline Dialysis & & & 0.060 \\
\hline (Yes) & $13(17.6)$ & $39(10.0)$ & \\
\hline (No) & $61(82.4)$ & $350(90.0)$ & \\
\hline Re-operation & & & $<0.001$ \\
\hline (Yes) & $29(39.2)$ & $71(18.3)$ & \\
\hline (No) & $45(60.8)$ & $318(81.7)$ & \\
\hline Biliary complication & & & 0.160 \\
\hline (Yes) & $12(16.2)$ & $41(10.5)$ & \\
\hline (No) & $62(83.8)$ & $348(89.5)$ & \\
\hline Hepatic artery complication & & & 0.849 \\
\hline (Yes) & $3(4.1)$ & $14(3.6)$ & \\
\hline (No) & $71(95.9)$ & $375(96.4)$ & \\
\hline Portal vein complication & & & 0.366 \\
\hline (Yes) & $0(0.0)$ & $8(2.1)$ & \\
\hline (No) & $74(100.0)$ & 381 (97.9) & \\
\hline & Page $14 / 17$ & & \\
\hline
\end{tabular}


Early allograft dysfunction

(Yes)

(No)

$$
0(0.0)
$$

74 (100.0)

Cardiovascular complication

(Yes)

(No)

Cerebrovascular complication

(Yes)

(No)

Pulmonary complication

(Yes)

(No)

Hemorrhage

(Yes)

(No)

Infection

(Yes)

(No)

Hospital mortality

(Yes)

(No)
$3(4.1)$

$71(95.9)$

$1(1.4)$

73 (98.6)

$12(16.2)$

$62(83.8)$

$13(17.6)$

$61(82.4)$

$28(37.8)$

$46(62.2)$

$9(12.2)$

$65(87.8)$
0.376

10 (2.6)

379 (97.4)

0.161

$6(1.5)$

383 (98.5)

1.000

$6(1.5)$

383 (98.5)

0.183

$42(10.8)$

347 (89.2)

0.099

42 (10.8)

347 (89.2)

0.187

117 (30.1)

272 (69.9)

0.030

$21(5.4)$

368 (94.6)

Note: model for end-stage liver disease (MELD) score, international normalized ratio (INR), graft-recipient weight ratio (GRWR), liver transplantation (LT)

Table 4. Comparisons of causes of mortality and surgical volume periods in hospital mortality of liver transplantation patients 


\begin{tabular}{|c|c|c|c|}
\hline & \multicolumn{2}{|c|}{ annual surgical volumes $<30$ annual surgical volumes $\geq 30$} & \multirow[t]{2}{*}{$\mathrm{p}$} \\
\hline & $\mathrm{n}=9(\%)$ & $\mathrm{n}=21(\%)$ & \\
\hline Infection & & & 0.465 \\
\hline Yes & $4(44.4)$ & $9(42.9)$ & \\
\hline No & $5(55.6)$ & $12(57.1)$ & \\
\hline Hemorrhage with/without infection & & & $<0.001$ \\
\hline Yes & $2(22.2)$ & $2(9.5)$ & \\
\hline No & $7(77.8)$ & $19(90.5)$ & \\
\hline Cerebrovascular with/without infection & & & $<0.001$ \\
\hline Yes & $1(11.1)$ & $2(9.5)$ & \\
\hline No & $8(88.9)$ & $19(90.5)$ & \\
\hline Cardiovascular with/without infection & & & 0.001 \\
\hline Yes & $2(22.2)$ & $4(19.0)$ & \\
\hline No & $7(77.8)$ & $17(81.0)$ & \\
\hline Early allograft dysfunction with infection & & & $<0.001$ \\
\hline Yes & $0(0.0)$ & $4(19.0)$ & \\
\hline No & $9(100.0)$ & $17(81.0)$ & \\
\hline
\end{tabular}

\section{Figures}

\section{LDLT number}

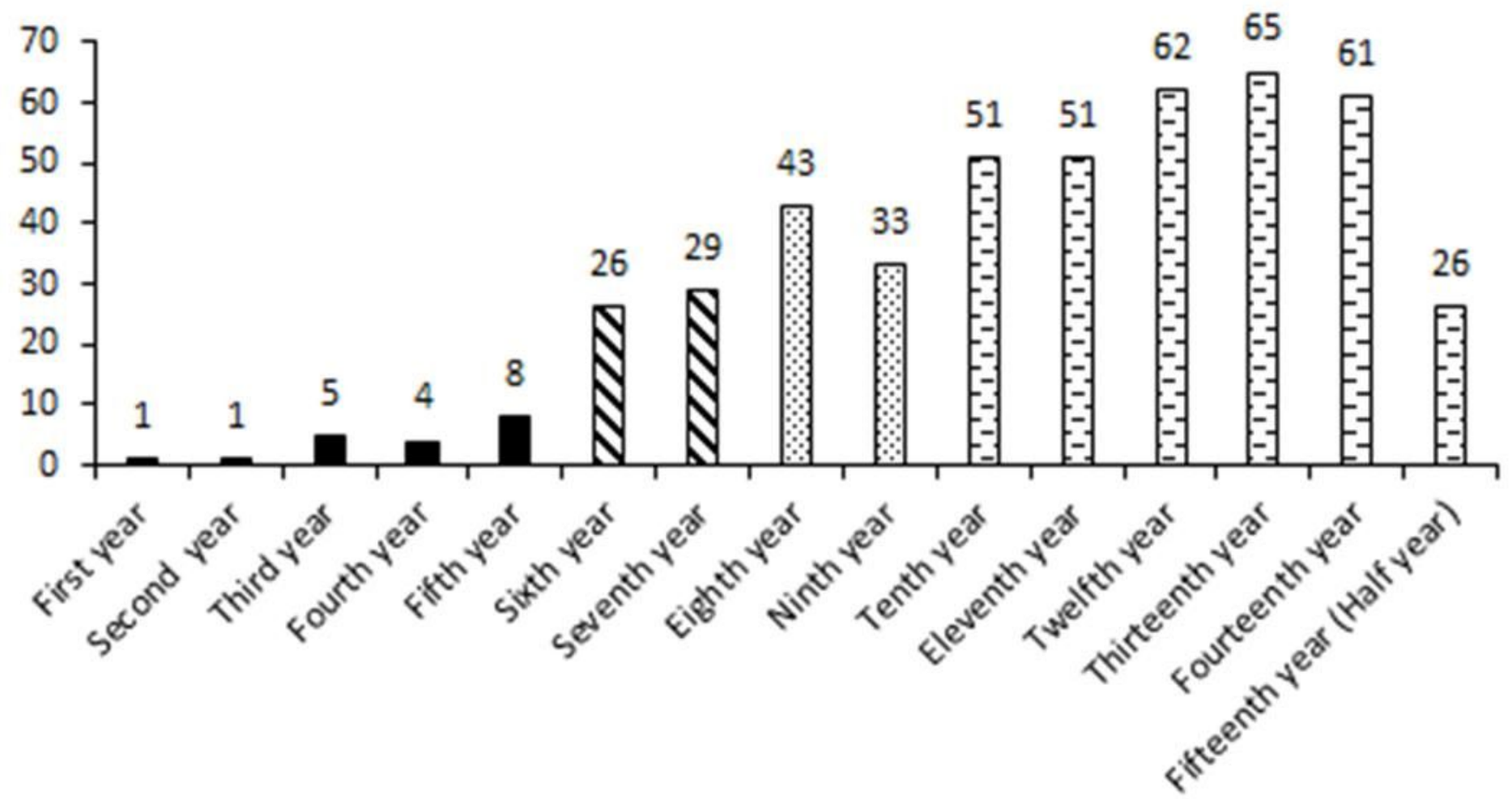

Figure 1 
Living donor liver transplantations in our center. Legend: Annual LDLT volume was less than 10 cases in the first 5 years of our transplantation center (total 19 transplantation cases). It grew to 20-30 cases in the 6th and 7th years, over 30 cases after 8 years, and over 50 cases after 10 years. 